\title{
Australia-Papua New Guinea Good Practice Scheme: Alotau-Sunshine Coast
}

\section{Doug Barnes}

Sunshine Coast Regional Council Queensland, Australia

\section{Adam Britton}

Sunshine Coast Regional Council Queensland, Australia
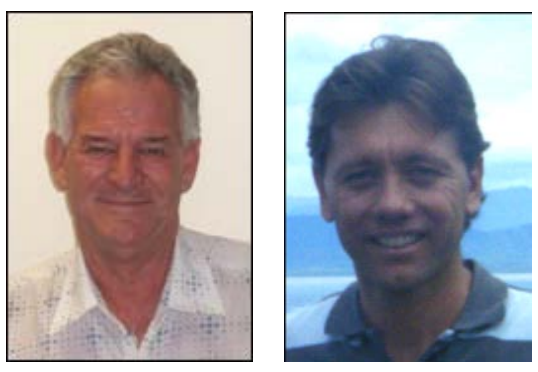

\section{Introduction}

In 2007 the CEO of the then Noosa Council became aware of the Commonwealth Local Government Forum's (CLGF) Good Practice Scheme in the Pacific program through his involvement as the President of Local Government Managers Australia. He contacted the CLGF with a view to contributing to the program. Alotau Urban Local Level Government (ULLG) was chosen as Noosa's partner for the program due to its enthusiasm to improve waste management practices in order to clean up the town and create an aesthetically improved environment. Noosa Council considered that it was well credentialed to assist in this regard. Later in November 2008, after Noosa had become part of the new Sunshine Coast Regional Council (SCRC) the Milne Bay Provincial Government and Alotau Urban Local Level Government (AULLG) sought further technical assistance for the preparation of an Urban Development Plan for Alotau and surrounds.

Alotau is a small coastal community (approx. 12,000 people) in the southeastern extremity of the Papua New Guinea (PNG) mainland. It is the administrative capital of Milne Bay and the key service centre for the numerous surrounding islands and villages. With an abundance of natural attributes, an expansive bay and foreshores and a forested backdrop overlooking the town, Alotau is emerging as a potential tourist destination and 
has significant capacity for further development and economic growth. There is, however, a lack of essential infrastructure such as roads, drainage, water supply, sewerage treatment, electricity and telecommunications to support future development and the growing population. Alotau is also constrained by the lack of easily developable land due to a number of issues including the township being surrounded by customary land, squatter housing, flood prone areas and general topography.

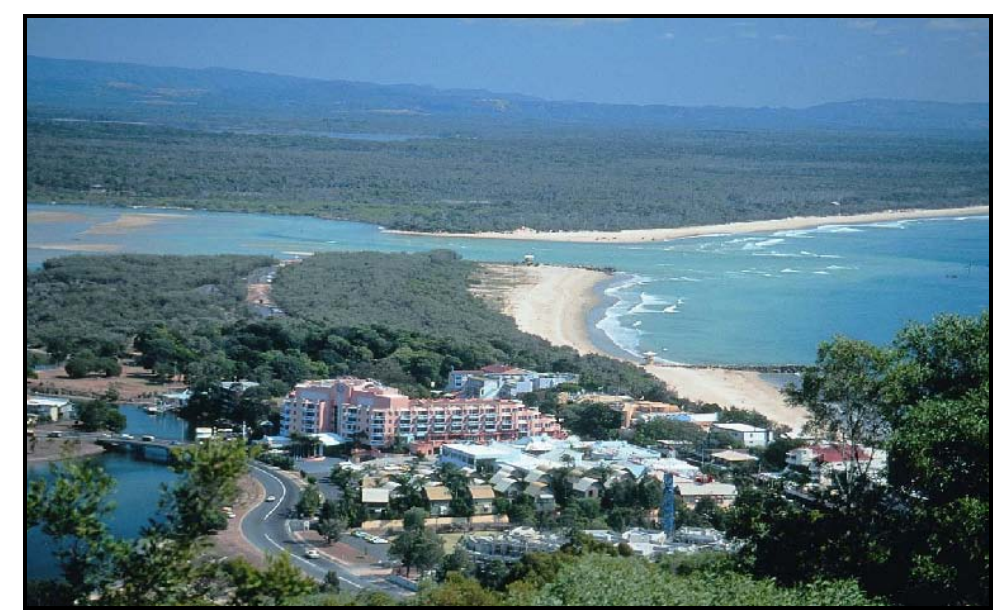

The Sunshine Coast, South East Queensland

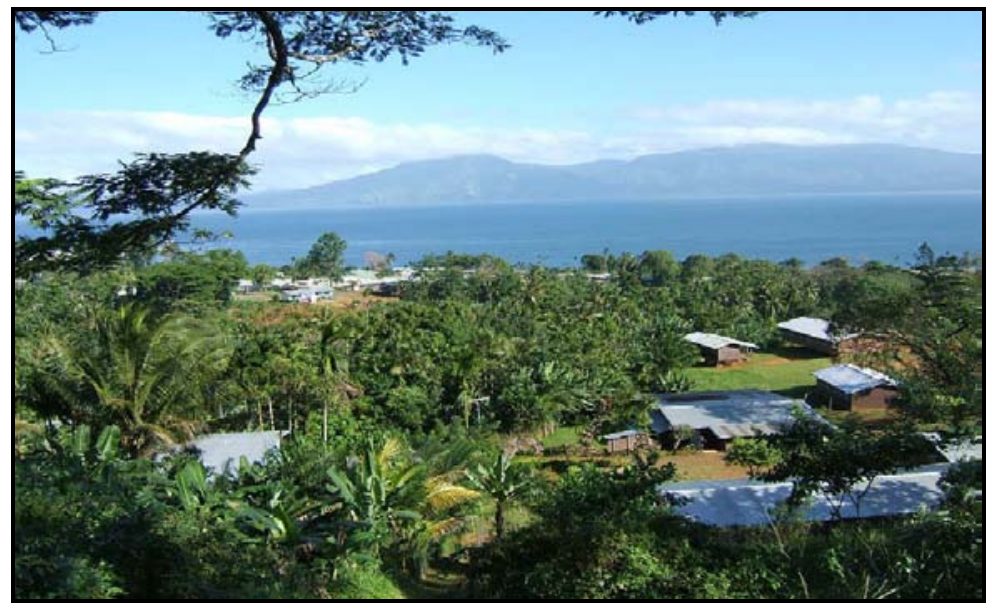

Alotau Town, Papua New Guinea

\section{Part A: Waste Management}

\section{Background}

A request by Alotau Urban Local Level Government (AULLG) was submitted to the Commonwealth Local Government Good Practice Scheme in the Pacific (CLGGPS) in early 2007 for assistance to improve waste management practices. The intention of AULLG was to improve waste management practices within the town in order to ensure 
that it was kept clean and tidy with a view to enhancing its natural beauty. A direct benefit of this would be Alotau's desire to become a tourist destination as the region has a huge potential for further development and the subsequent job creation this enhanced industry would bring. AULLG also needed assistance to ensure that waste management administration including budgeting and billing supported a sustainable program for the future.

A scoping visit by the Mayor and staff of Noosa Council was undertaken to establish the nature and scope of the required assistance. This visit established a relationship with the Mayor and staff of Alotau ULLG and confirmed that improvement in waste management was a priority need for Alotau ULLG. In December 2007, a memorandum of understanding (MoU) was signed. The Noosa Council has since amalgamated with the Maroochy and Caloundra Councils to form the Sunshine Coast Council (SCC), and it has agreed to honour the three partner MoU. SCC further developed a five-year program in conjunction with CLGGPS and AULLG, with funding provided through AusAID. SCC contributes in-kind resources in the form of staff time and expertise, and has also donated equipment (computers). To date, nine visits to AULLG have been undertaken by Council staff over a period of 3 years. Additionally, two staff members from AULLG were seconded to the SCC for training purposes for a period of 2 months and both gained valuable knowledge and experience during this time.

The partnership between CLGGPS in the Pacific, the AULLG and Sunshine Coast Council is progressing well. The partnership was extended in 2010 to include a project to assist the Milne Bay Provincial Government and the Alotau Urban Local level Government to develop a new planning scheme for the Town. A separate MoU has been drafted for this extension to the partnership.

\section{Context, Challenge and Approach}

The Waste Management Project was developed to address:

- A growing waste problem in Alotau compounded by population increase;

- Health issues associated with poor waste management;

- Income generation for the Urban Local Level Government; and

- Tourism potential. 
The challenges in developing the project included:

- Providing the 'tools' to address the problems - bins, trucks, landfill site, computers;

- Increasing public awareness;

- Funding availability - CLGGPS can only fund to a point; and

- Training across all levels of operation.

A needs assessment was established after the Technical Officer's visit that focused on the two key areas of training and the provision of vital equipment. The needs identified included:

- Training of waste management and clerical staff;

- Provision of a reliable waste collection service (refuse vehicles);

- Provision of litter facilities throughout the town (120 bins on stands);

- Provision of litter education to the community (Litter Control Committee);

- Provision of lidded bins for premises (1000 bins provided);

- Improvement in revenue generation and recovery;

- Improvement to the existing billing process;

- Provision of computers \& software for the billing process (8 laptops);

- Establishment of a recycling-reuse program; and

- Planning for a future new landfill.

\section{Progress update}

The progress achieved so far within the Waste Management Project includes:

2008

- A scoping visit and subsequent development of an action plan and budget.

- Signing of the MoU between CLGGPS/AULLG/Noosa Council.

- Repair to the road to the Alotau dump to enable wet season access.

- Reconfiguration of the dump site and burial of the accumulated rubbish.

- Provision of 7 computers and a printer, also provision of other computer accessories to enable electronic billing of waste accounts. These were second hand computers donated by SCC.

- Provision of training to AULLG staff in regard to billing and other accounting processes. 
- Secondment of the Alotau Health Inspector and the Deputy Manager from AULLG to the Noosa Council for training purposes.

- Provision of 60 street litter bin stands and 120x 240 litre garbage bins which have been installed throughout the Alotau Township and are serviced regularly.

- Provision of $300 \times 240$ litre garbage bins to AULLG that will be utilized to replace 44 gal drums used by commercial and residential premises within the Town. (600 more bins are required.) The bins will be sold to customers to assist in generating income for AULLG.

- Development of electronic billing software by SCC for AULLG and training of staff in use of the software. The software is now in use replacing the previous card file system.

- Review and amendment of the AULLG fees and charges for waste billing.

- Establishment of the Alotau Litter Control Committee (ALLCC). This committee consists of members of the business community in Alotau and also staff from AULLG and the Provincial Government. The committee has its own modest budget and has had an excellent impact on the litter education of the community and on cleaning up the Township.

- Arrangement has been undertaken to provide the AULLG with broadband internet services which will enable the SCC to remotely access the computers at AULLG and to repair and service the AULLG computer software as required from Sunshine Coast Council.

- Further training has commenced in regard to accountancy and billing processes.

- Various software programs have been developed and provided to the administrative staff at AULLG to enhance the billing process.

- Protective clothing has been provided to waste management workers including overalls, safety boots and gloves to protect their well being.

- The Health Inspector has been sent to attend WPH\&S certificate training in Port Moresby in order that WPH\&S measures can be applied within AULLG. 
- Work has commenced to secure the landfill from illegal dumping. Fencing and entrance gates are in the process of being installed at the landfill to ensure that illegal dumping does not occur.

- A Caretakers house (traditional house) is being constructed adjoining the landfill along with housing for the garbage truck labourers and their families. This process will also assist secure the landfill from illegal dumping and also assist in the collection of dumping fees at the dump.

- Further works are being undertaken to cover the waste on the dump and to recontour the landfill area and stormwater drainage.

- The access road to the dump is in the process of being regraded to ensure access throughout the wet season

- A further 600 wheelie bins (SULO) have been delivered to Alotau ULLG from Australia; these bins are now being distributed throughout the Town of Alotau.

- All computers have been serviced by the SCC team computer technician and cleared of any viruses. AULLG now has 10 working computers all have email service.

- The waste billing system is working well and outstanding accounts have decreased significantly.

- As a result of the introduction of the electronic billing system reducing labour time, a staff member of AULLG has now been reallocated from manual billing to working on reducing outstanding debts for waste services.

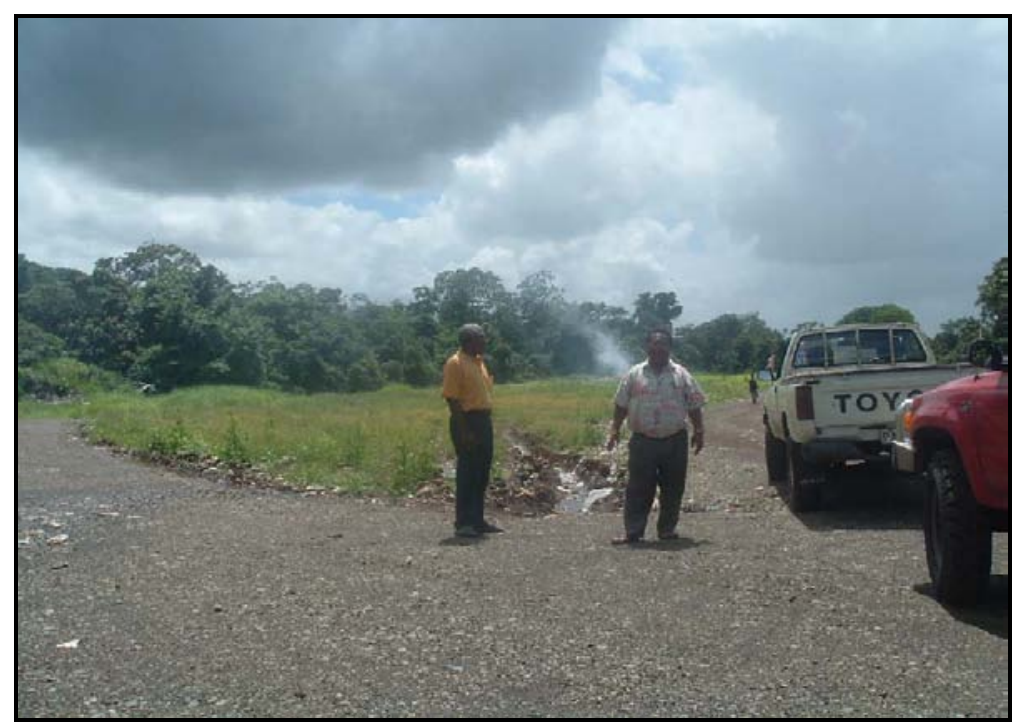

The Mayor and Town Manager inspect the reconstructed road to the dump 


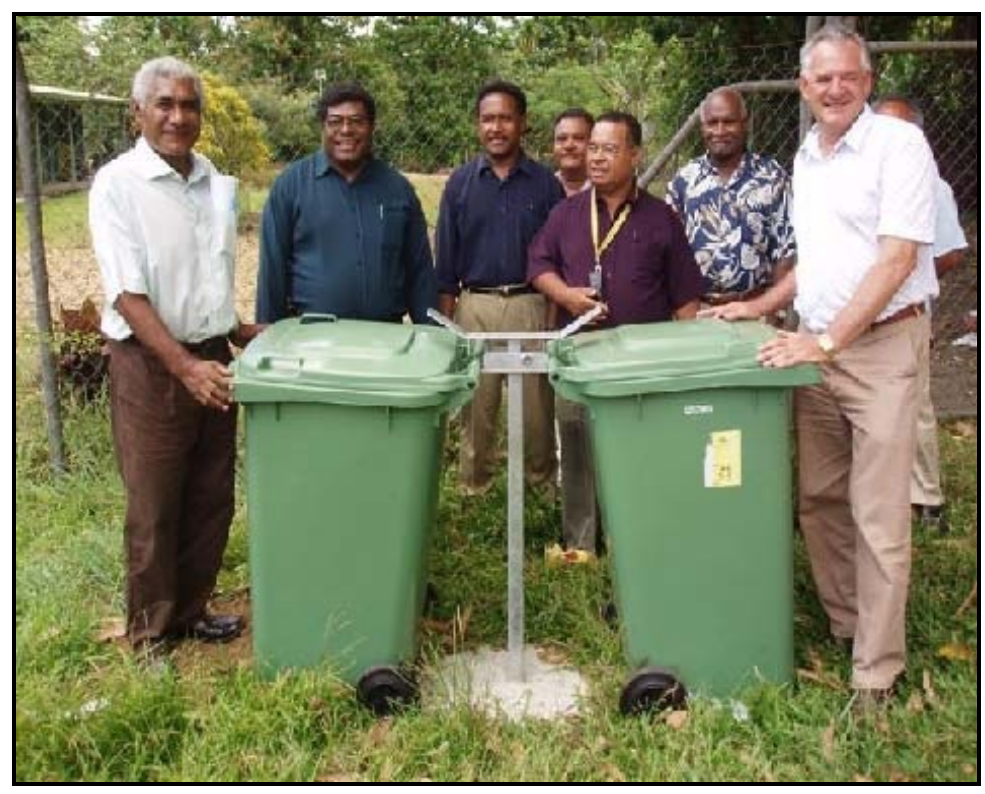

PNG local government staff with the new wheelie bins

- An audit of the number of bins located at each premise has been undertaken and an improved billing system is being developed to ensure that commercial premises pay for the quantity of refuse they produce based on the service frequency and number of bins serviced.

- Education of the public in regard to anti-littering is an ongoing process and is mainly implemented through the local radio station, however more remains to be done in this regard.

- Further training in accountancy and book keeping was provided to AULLG staff by SCC accountancy staff (visiting team member) the training has been very successful and rewarding for all concerned.

- The financial affairs of AULLG have improved considerably.

- The establishment and funding of a community based Litter Control Committee is an important milestone. The committee is responsible for education of the community in regard to "Keeping Alotau Clean". The use of the local radio station for promotion of anti litter measures has resulted in a large reduction in litter throughout the town.

\section{Future Challenges and Lessons Learnt}

The challenge for the partnership is to develop waste management practices that are both efficient and financially sustainable for the longer term. The partnership is progressing 
well and has achieved about $75 \%$ of its goals so far. In delivering the project the following challenges are to be overcome:

- Uptake of Bins - educate people of the benefits of new bins over old drum style.

- Accessible Dump site - costs to maintain access road and high rainfall impedes ability to use landfill site.

- Proper Billing and Finance - Without steady income the ability to sustain the project is affected.

- Reliable Trucks - Constant mechanical problems with trucks significantly affects the entire program.

The largest hurdle at this time is the final point; the provision and maintenance of refuse trucks to provide a reliable refuse collection service. The existing trucks were provided through the Provincial Government several years ago. The trucks are second hand and are subject to frequent break down, and their repair using local workshops is extremely expensive. The lack of reliability of the refuse service due to vehicle break downs encourages some customers not to pay their bills as the service is not always provided in a timely fashion.

\section{Options for conduct of the Refuse service}

Subject to AULLG continuing to gain an improved revenue flow, they may be able to borrow sufficient funds to purchase a new or second hand refuse truck in the future. AULLG would then continue to operate the refuse service as they do now. The business case for this procedure is being investigated. A further option is for AULLG to call for tenders for the conduct of the refuse service by a commercial waste company; this would require AULLG to pay a monthly payment for the collection services received. Investigation of this option has commenced. It may well be necessary to utilize an open tip truck for future waste collection services due to the high cost of a compactor truck. This option is also being considered.

\section{Future requirements}

The intended actions for the following calendar year include:

- Completion of traditional houses for caretaker and waste staff adjacent to the dump.

- Erection of gates and fences at the dump entrance. 
- Amendment to a local law in regard to waste fees and charges (Provincial Government solicitor actioning).

- Implementation of a producer pays policy for charging waste fees (for commercial premises).

- Continued financial support for the Alotau Community Litter Control Committee's educational program.

- Implementation of a training program for Alotau ULLG staff in the Microsoft suite of software programs.

- Investigation of a possible new landfill site as the Provincial Government wish to use the existing site for other purposes.

- Possible design of a new landfill site subject to a new location being offered.

- Ongoing training in financial management and accounting.

- Ongoing training in waste management practices.

- Ongoing information technology support.

- Secondment of selected Alotau ULLG staff to the SCC for training purposes.

- Investigation of a business case for provision of reliable waste collection trucks for the town.

- Further visits to Alotau ULLG to continue the support programs.

\section{Lessons learnt}

The Alotau Waste Management Project has been in operation for approximately 4 years now and there have been two clear lessons learnt for this project. The first is the need to ensure the project maintains momentum to prevent cyclic effects. For example:

- If bins are not emptied regularly complacency sets in and littering increases.

- If bins are not emptied the income to ULLG is affected.

- Reduced income affects the ability to maintain equipment which results in the ability to collect the bins. This cycle is difficult to break.

A second lesson concerns alternative ways of funding vital capital purchases:

- ULLG are constrained in their ability to get projects off the ground due to the high cost of items i.e. the purchase and regular maintenance of garbage trucks.

- GPS is not designed to fund capital purchases. 
Alternative funding options could be how contracts are established (i.e. contract out the waste collection and revenue return); involve the Provincial Government further i.e. consider lease and maintenance arrangements; or seek out other funding grants.

\section{Summary}

Excellent progress has been made over the past three years. Overall, waste management practices in general have improved, the Town is much cleaner, and the waste management billing system is now efficient. Staff administrative efficiency continues to improve. The potential exists to achieve excellent outcomes in Alotau over the next 4 years but in order for the program to be

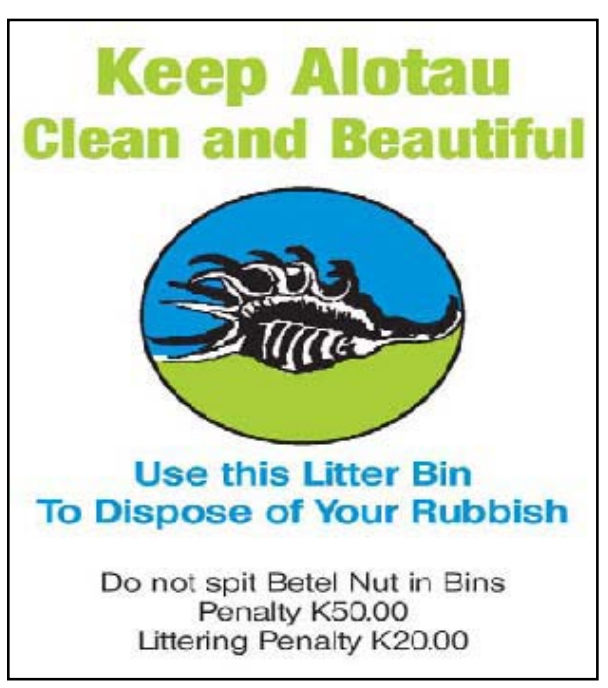
successful a reliable efficient waste collection service must be provided. A successful program will provide both public health and financial benefits to the Alotau community. In summary, Alotau ULLG is well on the way to becoming self sufficient and sustainable in regard to waste management practices, and staff are to be congratulated on their persistence in very difficult circumstances.

\section{Part B: Urban Development Plan}

\section{Background}

The urban development plan project is an extension of the work that has been ongoing since 2007 when SCRC (then Noosa Council) agreed to assist with waste management within Alotau. Since that time SCRC has assisted with the procurement of bins and setting up a budgeting and billing system for the AULLG to ensure sustainable long term waste management practices that will keep the town clean and tidy. This project is outlined below in more detail.

An existing urban development plan is currently in operation, but has officially expired and requires a comprehensive review. The proposed urban development plan is to be a strategic land use plan to guide the timely provision of future development and infrastructure for Alotau for a 20 year period until 2031. A number of preliminary studies are being prepared to identify the range of economic, social, environmental and 
infrastructure needs. The urban development plan will also include a detailed town centre plan of future community buildings and public open space, guidelines to improve existing and future buildings, designs to improve traffic and pedestrian flows, plans for upgrades to road works and stormwater drainage, and general streetscape improvement works. There will also be a works delivery program for government to use as a budgeting tool.

\section{February 2010 scoping visit}

An initial scoping visit was carried out in February 2010 which identified a number of priority needs that SCRC could assist with in the first instance, including:

- Initial capacity building and guidance for town planning and technical staff to get the project underway;

- Technical assistance with supporting planning studies, town centre plan and design guidelines;

- Assistance with the development of a GIS system and base mapping layers;

- Improving technical mapping skills;

- Provision of GPS equipment and mapping software;

- Technical advice around major infrastructure improvements such as roads, drainage, water, sewerage, marinas, power and telecommunications.

\section{Memorandum of understanding}

The government and administrative functions relating to physical planning (town planning) come under the responsibility of the Milne Bay Provincial Government and as such the provincial government is an additional partner to the SCRC-Alotau partnership. This requires a separate memorandum of understanding (MoU) to be signed by the SCRC, Commonwealth Local Government Forum (CLGF), AULLG and Milne Bay Provincial Government. This MoU has been drafted and is currently being finalised.

\section{Getting started: Town Planning Objectives and Issues}

The Alotau-Sunshine Coast Partnership allows for information sharing on Noosa's experience of achieving ecologically sustainable development and tourism. It also provides an insight and new skills for SCRC staff on urban development planning in a developing country whilst providing invaluable cultural experiences. The emphasis is on capacity building and skills development rather than task completion. The approach is to create a rapport and an understanding that the project is based on interaction and 
collaboration to build the capacity of local staff. At all times SCRC personnel ensure that they are considered as support staff and not as project managers or as lead consultants. This is vital to making sure that local staff do not consider themselves as subservient and that they retain ownership. With this ownership it is envisaged that the staff will not only gain the most in skill and personal development but that the plan is more likely to be understood and adopted into the future.

The main planning issues to be considered by the project team are:

- Incorporating the core social needs of the local people into the urban development plan;

- Defining and incorporating the key economic drivers for Alotau into the urban development plan;

- The processes around making customary land available for development;

- How to improve the roll out of residential housing land;

- How to minimize uncontrolled squatter housing;

- How to increase land for business;

- Upgrading existing infrastructure and relocating certain industrial activities;

- Allocation of land for major new infrastructure such as water and sewerage services;

- Impacts of future development on the natural environment and ensuring natural resources are sustainable for the long term;

- Creation of a more cohesive town character and general civic improvements.

The following actions were used to start the project:

- Preparation of a schedule of tasks and creation of a programme and budget around the required tasks;

- Meeting with relevant stakeholders;

- Review of existing data;

- Issue of information requests from relevant agencies;

- Meeting with political and administrative leaders to explain the project and the need for high level support;

- Providing technical assistance with the preparation of supporting planning studies on the range of economic, social, environmental and infrastructure needs; 
- Assistance with the preparation of the design brief for town centre plans and design guidelines for streetscape improvements, future community buildings and promoting traditional building character;

- Community and business surveys to gather the community's ideas and views about the future development of Alotau;

- Survey of existing land uses;

- Assistance with the development of a GIS mapping system to map property information, zoning, environmental values, etc;

- Improve in-house technical mapping skills through on the job training by National Lands Department staff and funding of technical university training;

- Provision of GPS equipment and mapping software.

\section{Progress update}

\section{Overview}

The most recent visit to Alotau by SCRC representatives in July and August was constructive in setting up and commencing work on background planning studies, community feedback surveys, project budgets, project briefs, land use surveys, and important base mapping. These tasks will all be progressed over the coming months in advance of the drafting of the urban development plan and its detailed land use and development requirements.

\section{Budget update}

Based on the priority needs identified during the scoping visit, a budget and supporting information was prepared to accompany a funding request to AusAID. A budget of just under \$50,000 was provided via the Commonwealth Local Government Fund in Port Moresby. There are a number of expenditure items in progress including further on the job mapping training, and the preparation of a socio-economic planning study. These are likely to be completed by the end of the year with a component carrying over into early January 2011.

\section{Tasks and achievements completed}

The project has maintained good momentum throughout the year with the main driving force coming from both AULLG and the Provincial Government 
Detail of progress achieved so far includes:

Confirmation of full scope of project - it was realised early into the visit that the project was a bigger task than first anticipated, requiring a large amount of background data, demographic interpretation and research before the drafting of the urban development plan could commence. The original project completion date of November 2010 was extended until late 2011, allowing for more in-depth investigation and reporting and a more accurate and effective town plan. SCRC staff were pleased to see how much work had been carried out since the scoping visit in February and the commitment shown by both levels of government, elected representatives and other community interests.

Government and community meetings - a number of meetings were held with high level staff and elected and community representatives during a 5 week visit in July/August. This included elected members Charles Abel and Gordon Wesley, the Provincial Administrator Henry Bailasi, Chamber of Commerce chairman, and Physical Planning Steering Committee Members. From these meetings there now appears to be strong local and provincial government enthusiasm and political support for the project. These are important for achieving good outcomes and ongoing resourcing.

Community and business surveys - a community feedback survey was distributed around the community to get an understanding of local people's views and preferences for the future. This was completed with the paid assistance of 10 (5 male, 5 female) local unemployed student graduates. Approximately 400 responses were received. A separate targeted business survey was also distributed to the chamber of commerce and business owners in Alotau. This was acknowledged to be the first time Alotau locals and businesses have had the opportunity to individually voice opinions on the future direction of their town.

Land use survey - data was collected over one week on the general use of all lands across the Alotau physical planning area. The Alotau Urban Local Level Government engaged a further 10 ( 5 male, 5 female) unemployed student graduates for this task. This data will be valuable for correlating intended and existing land uses. 
GIS mapping by national lands office staff - staff from Port Moresby Lands Office visited Alotau for a week to assist local staff with compiling mapping and survey data into a MapInfo Geographical Information System (GIS). Once completed, the GIS mapping for Alotau will be the first time the physical planning area has been accurately and digitally recorded in Alotau allowing for better land management. It is also being seen as a model for town planning in PNG for other provincial governments to follow.

Preparation of socio economic needs assessment brief for University of PNG - two project briefs were prepared for a Population and Housing Needs Assessment and an Economic and Employment Needs Assessment, with the University of PNG invited to complete the studies. The university has agreed to carryout the consultancy and is to commence work in November this year.

Preparation of town centre design brief - this brief provides the parameters for the detailed design of the local commercial centre including for future community buildings, streetscape improvement works, and the preparation of design guidelines for new commercial buildings. The provincial government have committed staff resources to complete the project in-house given their high level of architecture and design expertise. Emphasis will be placed on incorporating traditional design in keeping with the local culture.

Budget and future program - time was spent with government staff setting up a program and budget for completion of the project throughout 2010 and 2011.

\section{Reporting and information sharing}

Periodic reports to the CLGF are prepared to record the progress, achievements and future needs and recommendations. These reports are provided for their information and potentially distributed to other local governments interested in similar initiatives. Sunshine Coast Council also internally reports on the program benefits in terms of its social sustainability aims and outcomes. In addition, local staff report monthly to the Alotau Physical Planning Steering Committee on progress and to direct priorities 


\section{Future tasks, Suggestions and Lessons}

All of the currently funded project tasks have either been completed or have commenced and are due for completion early into 2011. The remaining work includes:

- Completion of the socio economic planning studies by the University of PNG;

- Completion of digitising of the land survey data and further assistance from National Lands Office with the GIS base mapping and zoning maps.

With the success to date, there is opportunity for the partnership to provide further guidance and capacity building with the urban development plan throughout 2011. Staff from Alotau have indicated that assistance would be valuable in the following areas:

- Drafting the Urban Development Plan;

- Town centre design and master planning; and

- IT technical support.

SCRC has prepared a draft budget submission for 2011 and are in correspondence with CLGGPS regarding the ongoing support.

\section{Suggestions and lessons}

Whilst there have been many challenges and impediments, they have not been significant enough to prevent progress. The challenges arise largely out of the complexity of the project and the nature of work in Papua New Guinea, and others relate to the operation of the program. Below is a brief list of those challenges to date, how they have been faced, and some lessons learnt.

- The time taken for approval and transfer of project funding from CLGGPS. Our experience is that there is need for a quicker turn around for identified projects to obtain CLGF approval. Staff often have other work commitments and require the earliest advice to organise travel dates.

- The initial lack of availability of funds from provincial government to assist in the preparation of the urban development plan had hindered the early stages of the project. This has since improved with the Provincial Government's allocation of K100,000 (approximately AUS\$39,600) into 2011. There is good strategic policy now coming from the national level (PNG Vision 2050) that will hopefully filter down locally to direct priorities and further funding around the role of good planning. 
- Difficulty in maintaining regular email communications. Alotau offices are subject to equipment and service faults and this will be an area of future work if it is approved under the program in 2011.

- Access to accurate data records has proved difficult. For example, the majority of survey cadastre files are still in hard copy and date back over 30 years. A large part of the current project to digitise the planning area should significantly improve access to accurate data.

- Lack of timely information impacts on the ability to assess it and include it into the urban development plan. For example the urban development plan requires specific input from other government agencies that are not able to provide information in the timeframe requested. It is hoped that ongoing liaison and involvement with the agencies through the preparation of the urban development plan will improve the provision of information.

- Personal challenges include how to deal with general health issues such as the risk of malaria, noting that the use of anti-malarials is not always an option.

- The other personal challenge is the perceived security risks when travelling via Port Moresby.

- Less of a challenge and more of a lesson from this project is how intergovernment relationships and cooperation adds significant value in achieving local project outcomes. The facilitation and use of National and Provincial staff expertise to add value locally could help coordinate the national roll out of successful project models such as Alotau's to other areas of PNG. It is also important that there is continued awareness of the CLGGPS capacity building program throughout all levels of government and in particular to distinguish itself from a traditional AusAID Capital Works program. Ideally this display of a unified government achieving outcomes for the local community may contribute to an improved public confidence in all levels of PNG government.

The partnership has gone well so far and the potential exists to achieve excellent outcomes for Alotau over the coming years. The preparation and completion of the urban 
development plan aims to be the first step for Alotau to clearly define its future over the next 20 years and deliver both community and economic expectations.

Postscript: Port Vila CLGGPS Workshop and Symposium

SCRC project staff Adam and Rebecca Britton presented an outline of this project at the CLGF Pacific Project Symposium and Commonwealth Good Practice Scheme Workshop in Port Vila in October 2010. There was agreement that the workshop provided valuable information regarding the other CLGGPS local government partnerships within PNG and areas for improvement in the way of information sharing. There are plans to set up a website for PNG-Australia partner councils to post information of mutual interest regarding program activities. 